\title{
INNOVATION AND IMPROVEMENT The SGIM TEACH Program: A Curriculum for Teachers
of Clinical Medicine
}

\author{
Christopher L. Knight, MD' , Donna M. Windish, MD, MPH², Steven A. Haist, MD, MS \\ Reena Karani, MD, MHPE 4 , Shobhina Chheda, MD, MPH', Michael Rosenblum, MD', \\ Preetha Basaviah, MD ${ }^{7}$, Abby L. Spencer, MD, MS ${ }^{8}$, and Eva M. Aagaard, MD ${ }^{9}$
}

'Division of General Internal Medicine, Department of Medicine, University of Washington School of Medicine, Seattle, WA, USA; ${ }^{2}$ Department of Internal Medicine, Yale University, New Haven, CT, USA; ${ }^{3}$ National Board of Medical Examiners, Philadelphia, PA, USA; ${ }^{4}$ Icahn School of Medicine at Mount Sinai, New York, NY, USA; ${ }^{5}$ Division of General Internal Medicine, Department of Medicine, University of Wisconsin School of Medicine and Public Health, Madison, WI, USA; ${ }^{6}$ University of Massachusetts Medical School-Baystate, Springfield, MA, USA; ${ }^{7}$ Stanford University School of Medicine, Palo Alto, CA, USA; ${ }^{8}$ Cleveland Clinic, Cleveland, OH, USA; ${ }^{9}$ Division of General Internal Medicine, University of Colorado School of Medicine, Aurora, CO, USA.

BACKGROUND: Demand for faculty with teaching expertise is increasing as medical education is becoming well established as a career pathway. Junior faculty may be expected to take on teaching responsibilities with minimal training in teaching skills.

AIM: To address the faculty development needs of junior clinician-educators with teaching responsibilities and those changing their career focus to include teaching.

SETTING: Sessions at two Society of General Internal Medicine (SGIM) annual meetings combined with local coaching and online learning during the intervening year. PARTICIPANTS: Eighty-nine faculty scholars in four consecutive annual cohorts from 2013 to 2016.

PROGRAM DESCRIPTION: Scholars participate in a fullday core teaching course as well as selective workshops at the annual meetings. Between meetings they receive direct observation and feedback on their teaching from a local coach and participate in an online discussion group. PROGRAM EVALUATION: Sessions were evaluated using a post-session survey. Overall content rating was 4.48 (out of 5). Eighty-nine percent of participants completed all requirements. Of these, 100\% agreed that they had gained valuable knowledge and skills.

DISCUSSION: The TEACH certificate program provides inexperienced faculty teachers an opportunity to develop core skills. Satisfaction is high. Future research should focus on the impact that this and similar programs have on teaching skills.

KEY WORDS: curriculum; faculty development; clinician-educator; teaching skills.

J Gen Intern Med 32(8):948-52

DOI: $10.1007 / \mathrm{s} 11606-017-4053-7$

(c) Society of General Internal Medicine 2017

Electronic supplementary material The online version of this article (doi:10.1007/s11606-017-4053-7) contains supplementary material, which is available to authorized users.

Received February 9, 2017

Revised March 9, 2017

Accepted March 17, 2017

Published online April 13, 2017

\section{INTRODUCTION}

The past 5 to 10 years in medical education have seen multiple forces converge to create increased demand for faculty with expertise in teaching. Accreditation bodies overseeing the education of both medical students and residents require that faculty are adequately prepared for teaching roles. ${ }^{1,2}$ Medical education is increasingly well recognized as a career pathway, with teaching skills serving as one criterion for excellence. ${ }^{3-5}$ The burden of needing proficiency in teaching but lacking opportunities to learn the requisite skills falls more heavily on junior faculty, a problem which has been especially noted in academic hospital medicine. ${ }^{6}$ While some institutions have developed local programs to train faculty in these requisite teaching skills, other institutions have yet to do so. Moreover, local programs may fail to meet the specific needs or time availability of general internist faculty. Our aim was to create a program to address the faculty development needs of junior clinician-educators in general internal medicine with new teaching responsibilities and seasoned clinicians changing their career focus to include teaching roles.

\section{SETTING AND PARTICIPANT RECRUITMENT}

The Teaching Educators Across the Continuum of Healthcare (TEACH) program combined in-person sessions and workshops at two Society of General Internal Medicine (SGIM) annual meetings with an online learning community. Participants were recruited through advertisement at the SGIM annual and regional meetings and through the online SGIM community forum. In addition, advertisements were sent through the Alliance for Academic Internal Medicine (AAIM) and the Association for Chiefs and Leaders in General Internal Medicine (ACLGIM). TEACH scholars were selected through a competitive application process. Applicants submitted a $\mathrm{CV}$, statement of interest, and description of current teaching activities. They also provided a letter of support from institutional leadership affirming sufficient funds 
and protected time for participation and identifying the individual who would serve as their on-site coach for direct observation and feedback (one with sufficient time, knowledge, and skills for the role). Primary selection criteria were a current or anticipated position requiring direct teaching, and congruence between the individual's learning goals and the objectives of the TEACH program.

\section{PROGRAM DESCRIPTION}

Program development began with a focused needs assessment conducted by the SGIM Education Committee.

\section{Needs Assessment}

The SGIM Education Committee developed a survey that was sent in May-June 2011 to all SGIM members self-identified as "clinician-educators" in order to determine their priorities for faculty development. Of 700 members surveyed, 229 (33\%) responded. Respondents ranked ten education topics/areas as high, medium, or low priority. Over 50\% rated curriculum development/evaluation, teaching skills, medical education research, and clinician-educator career development as a high priority. Interest in participating in a certificate program was also high, with $60 \%$ favoring offering of activities at the national SGIM meeting or online.

To assess the perspectives of university and community leaders in internal medicine education, the SGIM Education Committee surveyed members of ACLGIM and the Alliance of Independent Academic Medical Centers (AIAMC) in September 2011 about four areas of potential focus for our certificate offering: teaching skills, curriculum development and assessment, medical education leadership, and medical education research. The response rate for ACLGIM was 33\% (46/ 138 ) and for AIAMC was $15 \%$ (23/153). In both cohorts, the greatest interest was in a program in teaching skills, for which many respondents expressed a willingness to support attendance of junior faculty at a national program.

The SGIM Education Committee then conducted a search of medical education faculty development programs in North America and Europe, looking for both those that met the identified needs and those that could be used as models. The search revealed that many required a substantial commitment of time away from work and family or sizable tuition fees. Several programs targeted skills such as curriculum development or medical education research. Few targeted direct teaching skills (Appendix 1).

\section{Curriculum Development}

The TEACH steering committee, a subcommittee of the SGIM Education Committee consisting of ten individuals (nine faculty and one staff member) representing institutions spanning all regions of the US, was charged with developing the curriculum. Each member brought expertise in medical education, curriculum development, program implementation, faculty development, and mentoring.

The core curriculum was developed using cognitive constructivist learning theory and Ericsson's formulation of deliberate practice ${ }^{7}$ as theoretical frameworks. Specifically, the program was designed with the recognition that each of the participants comes to the program with different knowledge and experiences, that this information must be discussed and acknowledged as new skills are being taught, and that once taught, skills must be practiced with directed and iterative feedback and reflection. Throughout all elements of the curriculum, we worked actively to build a community of learners who would interact regularly as highlighted in social constructivist theory. ${ }^{8}$

Based on our needs assessment, we developed a list of topics valuable for junior clinician-educators and applicable to the daily work of general internists. The TEACH course steering committee took serial votes to prioritize the list, choosing four topics as core (establishing an effective learning climate, writing goals and objectives for learning, feedback and assessment, and introduction to the educator's portfolio) and six to be offered as selective (teaching as scholarship, didactic teaching, teaching in the ambulatory setting, teaching at the bedside, identification/remediation of the struggling learner, teaching in small groups). Core content was covered in a dedicated 1-day pre-course the day before the annual meeting (the Core Course), while selective topics were offered as workshops during the annual meetings, with three topics offered each year in a rotating fashion. Content was developed and delivered using review of the evidence and incorporating active learning methods including trigger videos, discussion, role play, and practice.

\section{Program Structure}

The Core Course consists of a combination of didactic and small group exercises intended to cover the core content, build community among TEACH scholars, and introduce them to the online and on-site portions of the curriculum. The selective workshops have learning objectives specified by TEACH but are designed and implemented by volunteer faculty. As part of the standard meeting program, selective workshops are open to all meeting attendees, not just TEACH scholars. This design was intended to provide an opportunity for the scholars to work together while also placing the course and the scholars within the larger context of the robust SGIM community dedicated to medical education.

After the scholars complete the Core Course and selective workshops at the SGIM annual meeting, they return to their home setting for the on-site and online portions of the program. The on-site coach is responsible for directly observing the scholar in their various teaching activities and providing guided feedback on how to improve. The on-site curriculum consists of a minimum of six observed teaching episodes in the scholar's choice of any of a variety of settings: bedside teaching, small group 
teaching, large group/lecture, and giving learners feedback. The TEACH program provides tools to facilitate structured feedback for each of these settings (Appendix 2). These tools were modified from tools published previously. ${ }^{9,10}$ Scholars post these assessments in an educator's portfolio so that the TEACH core faculty can provide additional feedback. Six was chosen as a number of assessments that would ensure adequate participation without undue burden, but additional observations are encouraged to take full advantage of the coaching relationships developed through TEACH.

The online portion of the curriculum consists of a discussion forum. The discussion forum provides a venue for a monthly journal club focusing on articles of importance to medical education and reinforcing and building on the topics covered in the in-person curriculum. Journals, TED talks, and questions were used to trigger discussion. Scholars were also encouraged to pose questions to and discuss challenges with their community of peer educators. The online component was monitored by the faculty and staff member.

An online portfolio provides scholars with a mechanism to document their teaching accomplishments, receive feedback, and prepare themselves for promotion. It was designed to be simple enough for a novice user, but sufficiently extensible that a comprehensive educator's portfolio could be created. TEACH scholars receive an online tutorial on how to create and maintain an electronic portfolio prior to the core course workshop, and this is reinforced during the pre-course and throughout the online journal club.

The cost of the TEACH program is $\$ 800$ for SGIM members and $\$ 1200$ for non-members. Participants must also attend at least one, and ideally two, SGIM annual meetings, with associated registration and travel costs.

\section{Participant Description}

Of 144 applicants, 92 participants (four cohorts of 21-25) have entered the program (Table 2). Of these 92, 64 have completed the program, with completion for 24 expected in 2017. In aggregate, the cohorts were $77.5 \%$ female, and $91 \%$ of scholars were at the instructor, assistant professor, or clinical assistant professor rank. Six (6.7\%) had no medical school faculty appointment (Table 1).

Table 1 Participant Demographics

\begin{tabular}{|c|c|c|c|c|}
\hline & 2013 cohort & 2014 cohort & 2015 cohort & 2016 cohort \\
\hline Female gender, $N(\%)$ & $18(75.0 \%)$ & $17(77.3 \%)$ & $18(85.7 \%)$ & $16(72.7 \%)$ \\
\hline \multicolumn{5}{|l|}{ Degree type, $N(\%)$} \\
\hline MD & $23(95.8 \%)$ & $21(95.5 \%)$ & $20(95.2 \%)$ & $22(100 \%)$ \\
\hline DO & $1(4.2 \%)$ & $1(4.6 \%)$ & $1(4.8 \%)$ & 0 \\
\hline MPH & $3(12.5 \%)$ & $1(4.6 \%)$ & $1(4.8 \%)$ & $3(13.6 \%)$ \\
\hline $\mathrm{PhD}$ & 0 & 0 & $1(4.8 \%)$ & $2(9.1 \%)$ \\
\hline \multicolumn{5}{|l|}{$\begin{array}{l}\text { Current medical school faculty } \\
\text { appointment, } N(\%)\end{array}$} \\
\hline Instructor & $2(8.7 \%)$ & $4(18.2 \%)$ & $1(5.3 \%)$ & $5(22.7 \%)$ \\
\hline Assistant professor & $13(56.5 \%)$ & $9(40.9 \%)$ & $15(78.9 \%)$ & $11(50 \%)$ \\
\hline Associate professor & 0 & $2(9.1 \%)$ & 0 & 0 \\
\hline Professor & 0 & 0 & 0 & 0 \\
\hline Clinical instructor & 0 & $2(9.1 \%)$ & 0 & $2(9.1 \%)$ \\
\hline Clinical assistant professor & $7(30.4 \%)$ & $2(9.1 \%)$ & $2(10.5 \%)$ & $3(13.6 \%)$ \\
\hline Clinical associate professor & 0 & 0 & 0 & 0 \\
\hline Clinical professor & 0 & 0 & 0 & 0 \\
\hline None & $1(4.4 \%)$ & $3(13.6 \%)$ & $1(5.3 \%)$ & $1(4.5 \%)$ \\
\hline \multicolumn{5}{|l|}{$\begin{array}{l}\text { Learners taught or mentored in } \\
\text { the last year, } N(\%)\end{array}$} \\
\hline Medical students & $22(91.7 \%)$ & $21(95.5 \%)$ & $20(95.2 \%)$ & $21(95.5 \%)$ \\
\hline Graduate students & $2(8.3 \%)$ & 0 & $4(19.0 \%)$ & $2(9.1 \%)$ \\
\hline Residents & $24(100 \%)$ & $22(100 \%)$ & $21(100 \%)$ & $21(95.5 \%)$ \\
\hline Fellows & $2(8.3 \%)$ & $4(18.2 \%)$ & $5(23.8 \%)$ & $4(18.2 \%)$ \\
\hline Physicians who have completed & $7(29.2 \%)$ & $6(27.3 \%)$ & $5(23.8 \%)$ & $5(22.7 \%)$ \\
\hline \multicolumn{5}{|l|}{ all medical training } \\
\hline \multicolumn{5}{|l|}{ Type of teaching, $N(\%)$} \\
\hline Clinical skills (history/physical exam) & $17(70.8 \%)$ & $19(86.4 \%)$ & $15(75 \%)$ & $12(54.5 \%)$ \\
\hline Problem-based learning & $5(20.8 \%)$ & $11(50.0 \%)$ & $4(20 \%)$ & $4(18.2 \%)$ \\
\hline Team-based learning & $5(20.8 \%)$ & $3(13.6 \%)$ & $8(40 \%)$ & $7(31.8 \%)$ \\
\hline Outpatient clinical & $20(83.3 \%)$ & $13(59.1 \%)$ & $18(90 \%)$ & $16(72.7 \%)$ \\
\hline Inpatient clinical & $19(79.2 \%)$ & $16(72.7 \%)$ & $17(85 \%)$ & $12(54.5 \%)$ \\
\hline \multicolumn{5}{|l|}{ Teaching settings in the last year, $N(\%)$} \\
\hline Own office practice & $14(58.3 \%)$ & $12(54.6 \%)$ & $12(57.1 \%)$ & $13(61.9 \%)$ \\
\hline House staff/resident clinic & $19(79.2 \%)$ & $18(81.8 \%)$ & $17(81 \%)$ & $15(71.4 \%)$ \\
\hline Inpatient team attending with house & $19(79.2 \%)$ & $18(81.8 \%)$ & $17(81 \%)$ & $12(57.1 \%)$ \\
\hline \multicolumn{5}{|l|}{ staff and/or students } \\
\hline Morning report or noon conference & $17(70.8 \%)$ & $14(63.6 \%)$ & $13(61.9 \%)$ & $15(71.4 \%)$ \\
\hline \multicolumn{5}{|l|}{ for house staff and/or students } \\
\hline Faculty development program & $10(41.7 \%)$ & $5(22.7 \%)$ & $5(23.8 \%)$ & $5(23.8 \%)$ \\
\hline CME workshop/course & $6(25.0 \%)$ & $5(22.7 \%)$ & $5(23.8 \%)$ & $10(47.6 \%)$ \\
\hline Other small group setting & $16(66.7 \%)$ & $18(81.8 \%)$ & $4(19.1 \%)$ & $5(23.8 \%)$ \\
\hline
\end{tabular}

CME continuing medical education 
Table 2 Assessment and Feedback of TEACH Course

\begin{tabular}{|c|c|}
\hline & $N(\%)$ total \\
\hline \multicolumn{2}{|c|}{ 1. After completing this course, have you acquired skills to...* $(N=84)$} \\
\hline $\begin{array}{l}\text { Begin building a national network of colleagues with } \\
\text { an interest in medical education }\end{array}$ & $83(98.8 \%)$ \\
\hline $\begin{array}{l}\text { Delineate and apply frameworks of developing an } \\
\text { effective learning climate }\end{array}$ & $84(100 \%)$ \\
\hline $\begin{array}{l}\text { Differentiate goals from objectives and write SMART } \\
\text { objectives for effective teaching }\end{array}$ & $84(100 \%)$ \\
\hline Distinguish between feedback and evaluation & $83(98.8 \%)$ \\
\hline Give effective feedback to learners and colleagues & $82(97.6 \%)$ \\
\hline \multicolumn{2}{|c|}{$\begin{array}{l}\text { 2. I will make the following changes in my teaching as a result of this } \\
\text { course }^{\dagger}(N=76)\end{array}$} \\
\hline $\begin{array}{l}\text { Write clearer and more deliberate goals and } \\
\text { objectives }\end{array}$ & $53(69.7 \%)$ \\
\hline Provide more deliberate and specific feedback & $25(61.8 \%)$ \\
\hline Be more reflective as a teacher & $3(3.9 \%)$ \\
\hline Conduct more bedside rounds or teaching & $5(6.6 \%)$ \\
\hline Establish a more favorable learning climate & $7(9.2 \%)$ \\
\hline Keep track of all teaching/develop a portfolio & $7(9.2 \%)$ \\
\hline \multicolumn{2}{|l|}{ 3. Feedback and suggestions for change $(N=57)$} \\
\hline Program did not need change & $15(26.3 \%)$ \\
\hline Faculty were enthusiastic, approachable, dynamic & $10(17.5 \%)$ \\
\hline $\begin{array}{l}\text { Small groups worked well but could have been } \\
\text { allocated more time }\end{array}$ & $10(17.5 \%)$ \\
\hline More breaks needed & $4(7 \%)$ \\
\hline More time for networking/mentoring & $4(7 \%)$ \\
\hline Provide access to slides/handouts in advance & $3(5.3 \%)$ \\
\hline More time for discussion/activities & $2(3.5 \%)$ \\
\hline Role plays worked well & $1(1.7 \%)$ \\
\hline Provide more challenging feedback scenarios & $1(1.7 \%)$ \\
\hline Include additional content (assessment, pedagogy) & $2(3.5 \%)$ \\
\hline
\end{tabular}

*Reported ratings were for those who said agree or strongly agree

${ }^{\dagger}$ The question was open-ended, and more than one response was given by participants in most cases

${ }^{7}$ In total, 38 of 46 participants provided comments. Not all comments were legible and could be listed

\section{PROGRAM EVALUATION}

Initial evaluation of the core course was conducted through an online participant survey immediately afterward. The overall rating of the course content was 4.48 and course faculty was $4.68(1=$ poor, 5 = outstanding $)$. Across all years, $100 \%$ of participants agreed that they gained valuable knowledge and skills that would help them in their teaching role. Participants agreed or strongly agreed (97.6-100\% of participants) that the course met all the specific learning objectives it intended to address. Most participants (84.9\%) found "Writing Goals and Objectives for Teaching" session to be the most useful, with "Feedback and Assessment" as the next most useful (70.8\%). When asked what changes they would make because of the course, more than half reported they would write clearer and more deliberate goals and objectives $(69.7 \%)$ and provide more deliberate and specific feedback to their learners (61.8\%; Table 2).

At the end of each course, we asked the participants for feedback or suggestions for change (Table 2). The most common response was that the program did not require change (15 of 57 comments, $26.3 \%$ ). Having more time for small group work and the strength of the faculty were noted as the second most frequent responses (each 17.5\%).

\section{DISCUSSION}

TEACH is a novel certificate program that draws on theories of deliberate practice and social constructivism while teaching evidence-based educational practices. The program's goal is to provide inexperienced faculty with core teaching skills while building a community of educators within SGIM. In doing so, TEACH meets an expressed need for faculty, their institutions, and the national organization. The program has successfully recruited to capacity each year, and the coursework is highly rated by learners. Participants report that they will make fundamental changes to their teaching. We do not yet know whether the program results in actual improvements in teaching skills, although we feel confident that the program utilizes best practices in faculty development.

The most challenging parts of the course have been the online community and electronic teaching portfolio. Most, but not all, of the scholars participate in monthly online discussions consistently. The electronic teaching portfolio has presented a technical challenge for some scholars. This problem was mitigated somewhat by spacing out portfolio assignments throughout the year in the second TEACH cohort. We also added an option for document-based portfolios to accommodate those participants who did not want to use the online portfolio and those who needed to submit a documentbased portfolio for promotion.

An unanticipated and very positive outcome was the strong desire among finishing scholars to remain engaged with the program. Although we were unprepared for this in the first cohort, their enthusiasm led us to create a second, shorter didactic and interactive session ("TEACH 201") for those finishing the TEACH curriculum, which debuted in 2015. We also supported a subset of the first TEACH cohort who chose to continue to participate in a self-organized online journal club.

The true long-term success of this program will be measured over the course of scholars' careers, and by the impact of the program on their teaching. We have created a program that provides new teachers with a knowledge base in direct teaching, an opportunity to practice skills with expert feedback, and an introduction to a community of fellow educators who will help them thrive.

Acknowledgements: The authors would like to thank Julie Machulsky for her contributions to the TEACH program, and Michael Landry, MD, MSc, and Gary Rosenthal, MD, for their counsel and support. The TEACH program is funded by the Society of General Internal Medicine.

Corresponding Author: Christopher L. Knight, MD; Division of General Internal Medicine, Department of MedicineUniversity of Washington School of Medicine, Seattle, WA, USA (e-mail: cknight@uw.edu).

\section{Compliance with Ethical Standards:}

Conflict of Interest: The authors declare that they do not have a conflict of interest. 
IRB Approval: The TEACH program was reviewed by the University of Colorado Institutional Review Board and determined to be exempt.

\section{REFERENCES}

1. Liaison Committee on Medical Education. Functions and structure of a medical school. Available at: http://www.lcme.org/publications/functions.pdf. Accessed October 24, 2014.

2. Accreditation Council for Graduate Medical Education. ACGME Common Program Requirements. Available at: http://www.acgme.org/Portals/0/ PFAssets/ProgramRequirements/CPRs_07012016.pdf. Accessed March 17, 2017.

3. Roberts DH, Schwartzstein RM, Weinberger SE. Career development for the clinician-educator. Optimizing impact and maximizing success. Ann Am Thorac Soc. 2014;11(2):254-9.

4. Sabel E, Archer J, Early Careers Working Group at the Academy of Medical Educators. "Medical education is the ugly duckling of the medical world" and other challenges to medical educators' identity construction: a qualitative study. Acad Med J Assoc Am Med Coll. 2014;89(11):1474-80.
5. Atasoylu AA, Wright SM, Beasley BW, et al. Promotion criteria for clinician-educators. J Gen Intern Med. 2003;18(9):711-6.

6. Flanders SA, Centor B, Weber V, McGinn T, DeSalvo K, Auerbach A. Challenges and opportunities in Academic Hospital Medicine: report from the Academic Hospital Medicine Summit. J Hosp Med. 2009;4(4):240-6.

7. Ericsson KA. Deliberate practice and the acquisition and maintenance of expert performance in medicine and related domains. Acad Med J Assoc Am Med Coll. 2004;79(10 Suppl):S70-81.

8. UC Berkeley Graduate Student Instruction Teaching \& Resource Center. Social Constructivism. Available at: http://gsi.berkeley.edu/gsi-guidecontents/learning-theory-research/social-constructivism/. Accessed March 17, 2017.

9. Zenni E, Hageman H, Hafler J, Gusic M. Peer Feedback Tool for Clinical Teaching. MedEdPORTAL Publications; 2011. Available from: https:// www.mededportal.org/publication/8560. Accessed March 17, 2017.

10. Blanco M, Capello C, Gusic M, McCormack W, Hafler J. Peer Feedback Tool for Lectures \& Small Group Teaching. MedEdPORTAL Publications; 2011. Available from: https://www.mededportal.org/publication/8416. Accessed March 17, 2017. 